CAmerican Psychological Association, 2021. This paper is not the copy of record and may not exactly replicate the authoritative document published in the APA journal. Please do not copy or cite without author's permission.

\title{
Emotion Regulation and Self-Criticism in Children and Adolescence: Longitudinal networks of transdiagnostic risk factors
}

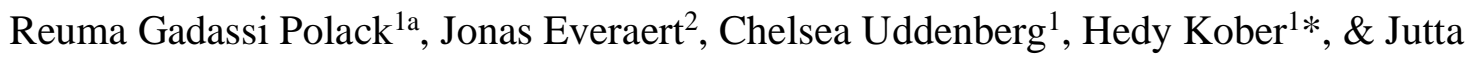
Joormann $^{1 *}$

${ }^{1}$ Yale University, ${ }^{2}$ Tilburg University

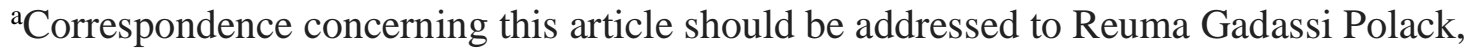
Department of Psychology, Yale University, 2 Hillhouse Avenue, New Haven, CT, 06520. Email: reuma.gadassipolack@yale.edu.

* These authors contributed equally

Running Head: Self-criticism and emotion regulation networks

Conflict of Interests. All authors declare no conflict of interests.

Data Availability Statement. Data and R scripts used for analyses are available upon demand from the first author.

Acknowledgments. This project has received funding from the European Union's Horizon 2020 research and innovation programme under the Marie Skłodowska-Curie grant agreement No. 786064, the National Institute of Mental Health Translational Developmental Neuroscience Training Grant (T32 \#MH18268), The Israeli Council for Higher Education Postdoctoral Research Fellowship for Women awarded to Dr. Gadassi Polack, by a postdoctoral fellowship from the Research 
CAmerican Psychological Association, 2021. This paper is not the copy of record and may not exactly replicate the authoritative document published in the APA journal. Please do not copy or cite without author's permission.

Foundation - Flanders (1202119N) awarded to Dr. Jonas Everaert, and the National Institute of Mental Health R21 MH119552 awarded to Dr. Joormann and Dr. Kober. The authors would like to thank Haran Sened and Itay Polack Gadassi for their help setting up the study, to the research assistants who helped with data collection, and to the families who participated. 
CAmerican Psychological Association, 2021. This paper is not the copy of record and may not exactly replicate the authoritative document published in the APA journal. Please do not copy or cite without author's permission.

Research Highlights

- This is the first study to use network analysis of an intensive longitudinal design to examine how risk factors for psychopathology interact

- Emotion regulation strategies were positively associated at the between- and withinperson networks

- Problem-solving, usually considered adaptive, surprisingly lead to next-day increases in rumination and dampening

- Self-criticism, rumination, dampening, and problem-solving were inter-related in all three networks

- Distraction in response to negative mood was positively associated with positive ruminations, forming a protective triad 
CAmerican Psychological Association, 2021. This paper is not the copy of record and may not exactly replicate the authoritative document published in the APA journal. Please do not copy or cite without author's permission.

\begin{abstract}
Adolescence is a time of heightened risk for the development of psychopathology. Difficulties in emotion regulation and heightened levels of self-criticism are two processes that have been proposed as critical risk factors. Considering the accumulating evidence that risk factors rarely work in isolation, there is a pressing need to examine how self-criticism and emotion regulations strategies interact. The present study utilizes a network analysis approach to address this goal. One-hundred and thirty-five children and adolescence (ages 815) completed daily-diaries every evening for 21 days (total $\mathrm{N}$ of assessments $=2564$ ), reporting self-criticism and use of emotion regulation strategies focused on negative and positive emotions. Network analysis was applied to estimate contemporaneous, temporal, and between-person networks. Results show that emotion regulation strategies are generally positively associated with each other at the within and between individual levels. As predicted, self-criticism was positively associated with rumination and dampening at the between and within-person networks; unexpectedly, problem-solving also clustered with them in the contemporaneous network. Moreover, problem-solving led to next-day increases in rumination and dampening, whereas self-criticism led to next-day increases in rumination but decreases in dampening. Finally, distraction in response to negative affect was closely tied with strategies that up-regulate positive affect. Collectively, these results shed light on the complex pathways through which self-criticism and emotion regulation interact over time.
\end{abstract}

Keywords: emotion regulation, self-criticism, adolescents, daily diary, network analysis 
CAmerican Psychological Association, 2021. This paper is not the copy of record and may not exactly replicate the authoritative document published in the APA journal. Please do not copy or cite without author's permission.

\section{Emotion Regulation and Self-Criticism in Children and Adolescence: Longitudinal networks of transdiagnostic risk factors}

Adolescence is marked by many significant social, psychological, and biological changes, including increased emotionality and changes in brain development (Rapee et al, 2019). Two critical developmental challenges during adolescence are the development of self-concept and heightened emotionality (Compas et al, 2017; Harter, 2015; Rapee et al, 2019). Although most children and adolescence successfully cope with these challenges, others do not, and may be at increased risk for the developmnt of psychopathology. Indeed, several disorders emerge or significantly increase during adolescence (e.g., depression, social anxiety; Kessler, Chiu, Demler \& Walters, 2005). Many of these disorders are characterized by heightened dysregulation of negative mood and distress regarding social evaluation (Casey, Oliveri \& Insel, 2014; Rapee et al, 2019; Rodman, Powers, \& Somerville, 2017).

\section{The development of self-concept}

A central developmental challange during adolescence is the development of a positive self-concept (Becht et al, 2016; Klimstra et al, 2016; Pfeifer \& Berkman, 2018; Rapee et al. 2019). During adolescnce, children begin to depend on their caregivers less and develop their independent self-concept (Blatt \& Zuroff, 1992; Kopala-Sibley, Zuroff, Hankin \& Abela, 2015), which becomes more complex and differentiated (Barendse et al, 2020; Byrne \& Shavelson, 1996; Harter, 2015; Pfeifer, et al, 2018). Deficits in the development of self-concept during adolescence lead to higher levels of self-criticism (Kopala-Sibley et al, 2015).

Higher levels of self-criticism prior to adulthood is associated with increased vulnerability to emotional disorders that often emerge during adolescence, including 
CAmerican Psychological Association, 2021. This paper is not the copy of record and may not exactly replicate the authoritative document published in the APA journal. Please do not copy or cite without author's permission.

depression, eating disorders, and social anxiety (e.g., Blatt \& Zuroff, 1992; Fennig, Hadas, Itzhaky, Roe, Apter \& Shahar, 2008; Kopala-Sibley, Zuroff, Russell \& Moskowitz, 2014). Given the involvement of negative self-referential processing in many disorders, research on self-criticism in adolescence is particularly important (e.g., Lemogne, Delaveau, Freton, Guionnet, \& Fossati, 2012).

\section{Emotion dysregulation}

Adolescence is a developmental period characterized by an imbalance between increased emotionallity and protracted development of regulatory circuits, rendering adolescents particularly vulnerable to the development of emotional disorders (Casey, Duhoux \& Cohen, 2010). Thus, another developmental challenge for adolescents is learning how to regulate their emotions. In contrast to infancy and childhood, when regulation largely depends on the caregiver (Eisenberg, Spinrad \& Eggum, 2010), adolescents need to learn how to regulate their emotions independently. Multiple studies have shown that deficits in emotion regulation is associated with increased risk for psychopathology in adolescence and beyond (e.g., Mennin, Holoway, Fresco, Moore \& Heimberg, 2007; Nolen-Hoeksema, Stice, Wade \& Bohon, 2007; Flett, Coulter, Hewitt \& Nepon, 2011; Svaldi, Griepenstroh, TuschenCaffer, \& Ehring, 2012; Dixon-Gordon, Aldao \& De Los Reyes, 2014; Compas et al, 2017).

Although self-criticism is sometimes conceptualized as an emotion regulation strategy (e.g., Aldao \& Nolen-Hoeksema, 2012), only a few studies examined how self criticism and emotion regulation interact. A prospective longitudinal study with adolescents showed that a self-evaluative vulnerability (assessed using perfectionism and self-worth contigencies, which are closely related to self-criticism) predicted changes in rumination over a period of three months (Burwell, 2015). Another study characterized self-criticism as a feature of state rumination in an adult sample (Bernstein et al., 2017). However, no studies, to our 
CAmerican Psychological Association, 2021. This paper is not the copy of record and may not exactly replicate the authoritative document published in the APA journal. Please do not copy or cite without author's permission.

knowledge, examined how self-criticism is related to other emotion regulation strategies.

This gap is concerning because a positive self-concept is closely related to motivational, affective, and regulatory processes in adolescence (Pfeifer \& Berkman, 2018; Pfeifer et al, 2013). The study of associations among risk factors is essential to understanding how the incidence of psychopathology increases in adolescence, in order to prevent the onset of these disorders in adolescents and later in life (Everaert, Bernstein, Joormann, Koster, 2020).

Another lacuna in the literature on emotion regulation in children and adolescence, is that most research focused on the individual contribution of specific emotion regulation strategies. However emotion regulation strategies usually work in concert (Ford, Gross, \& Gruber, 2019). Accordingly, recent studies on emotion regulation in children and adolescence started focusing on profiles of emotion regulation strategies (e.g., te Brinke et al, 2020; van den Huevel, 2020; Zhang et al, 2019). These type of investigations cluster participants into separate groups according to similar emotion regulation profiles. For example, "high regulators" are children and adolescence who use both putatively adaptive and maladaptive emotion regulation strategies more than average (van den Huevel., 2020). However clustering individuals into groups, although informative about individual differences, does not inform us about how emotion regulation strategies interact with each other.

One meta-analysis based on 280 studies focusing on how emotion regulation strategies cluster together (Naragon-Gainey et al, 2017) revealed a three-factor structure: (1) Disengagement involves shifting attention to less emotionally salient stimuli (e.g., distraction, low emotion-focused, and self-focused positive rumination); (2) Aversive Cognitive Perseveration is characterized by overattention to negative cognitions (e.g., rumination and dampening); and (3) Adaptive Engagement involves a focus on altering a situation (e.g., problem solving, reappraisal). Importantly, results from this meta-analysis indicate that the 
CAmerican Psychological Association, 2021. This paper is not the copy of record and may not exactly replicate the authoritative document published in the APA journal. Please do not copy or cite without author's permission.

correlations among different strategies is stronger for adolescents (vs. adults). A main limitation of the studies examining individuals' profiles or the clustering of emotion regulation strategies is their cross-sectional design, which limits our ability to understand how within-person dynamics of emotion regulation strategies emerge.

Two studies, conducted on adults, examined how emotion regulation strategies clustered across individuals and over time, using an intensive longitudinal design (Grommisch et al., 2020; McMahon \& Naragon-Gainey, 2018). McMahn and NaragonGainey (2018) examined the use of 11 emotion regulation strategies in a sample of 109 college students who completed a 14-day daily diary and a sample of 129 treatment-seeking adults who completed a 10-day Ecological Momentary Assessment (EMA) with three daily assessments. Using multilevel exploratory factor analysis, they uncovered different factor structures in the between- and within-person levels, which were largely similar in the two samples. On the between-person level, a two-factor structure emerged in both samples. One factor included putatively adaptive emotion regulation strategies and was referred to as engagement (including reflection, social support, savoring, acceptance, and reappraisal), whereas the other factor included putatively maladaptive strategies and was referred to as avoidance (including rumination, behavioral avoidance, distraction, procrastination, and expressive suppression). At the within-person level that examined which strategies were used at the same time-point, a four-factor structure emerged in the student sample: attentional shift (including reappraisal, reflection, and experiential avoidance), acceptance (including acceptance and savoring), avoidance (distraction, rumination, procrastination, and behavioral avoidance), and emotion expression (low expressive suppression and high social support). The factor structure in the clinical sample was similar, though it did not include the acceptance factor. 
CAmerican Psychological Association, 2021. This paper is not the copy of record and may not exactly replicate the authoritative document published in the APA journal. Please do not copy or cite without author's permission.

Similarly, Grommisch et al (2019) examined the use of 10 emotion regulation strategies in a sample of 179 adults who completed a 21-day EMA with 9-10 daily assessment. Instead of factor analysis, Grommisch et al (2019) employed a multilevel latent profile analysis to examine how emotion regulation strategies focusing on negative emotions cluster over time. Similarly to McMahon and Naragon-Gainey (2018), they too found different clustering in the between- and within-person levels. At the between person levels, five profiles emerged. Three profiles included participants who used all emotion regulation starategies to the same degree, and differed only in the frequency of regulation (very frequent regulation using all strategies, medium frequency, and very rare regulation). Two remaining profiles showed preference to some strategies over others - one profile was characterized by using mostly active regulation (situation selection, situation modification, acceptance, and social sharing), whereas the other profile was characterized by suppression-focus (a putatively maladaptive strategy). On the within-person level, nine profiles were identified. Similar to person levels, three profiles were characterized by similar use of all strategies at different frequencies, and six profiels in which specific strategies were used more than others: (1) situation selection and acceptance, (2) situation modification, (3) social sharing with situation modification, (4) suppression with situation modification, (5) suppression with ignoring, and (6) social sharing profile.

The results of both studies showed that emotion regulation strategies clustered differently at the between and within-person levels, and that at least on the person-level, strategies may cluster based on how maladaptive or adaptive they are. The within-person results were more variable and thus more difficult to summarize. Importantly, though both studies examined a large number of emotion regulation strategies, only one of those studies examined a strategy focusing on positive emotion regulation (McMahon \& Naragon-Gainey, 
CAmerican Psychological Association, 2021. This paper is not the copy of record and may not exactly replicate the authoritative document published in the APA journal. Please do not copy or cite without author's permission.

2018). Research on the simultaneous use of different emotion regulation strategies - of both negative and positive emotion - is especially necessary in adolescents, who are beginning to learn how to select between different emotion regulation strategies as their cognitive capabilities develop (Dixon-Gordon, Aldao \& Reyes, 2015; Zimmer-Gembeck \& Skinner, 2011; Naragon-Gainey, McMahon, \& Chacko, 2017).

Previous studies that examined how emotion regulation strategies are employed in concert used statistical methods that cluster strategies or the individuals using them, into specific groups (Grommisch et al., 2020; McMahon \& Naragon-Gainey, 2018). To go beyond these important findings, the present investigation aimed to understand the interplay between emotion regulation strategies and self-criticism. To do so, we employed network analysis. Networks consist of nodes and edges, where nodes represent the main variables of interest (e.g., self-criticism, strategies) and edges represent the connections between nodes (Borsboom \& Cramer, 2013). In addition to providing information about how the nodes cluster together, network analysis can uncover the interaction between them, such as feedback loops (Borsboom \& Cramer, 2013). When based on data from intensive longitudinal designs, network analysis can examine not just between-person associations, but can also examine contemporanous and temporal relations among the nodes. In turn, this can help us develop a comprehensive understanding of which risk factors act at the same time, and which precede one another (English \& Eldesouky, 2020; Hoorelbeke, Van den Bergh, Wichers, Koster, 2019). Thus, the comprehensive interactive networks that are uncovered by this analysis can help us achieve a more complete understanding of risk mechanisms

\section{The Present Study}

The present study extends the literature on self-criticism in adolescents by using intensive longitudinal data instead of a one-time assessment (or 2-3 times, in the case of 
CAmerican Psychological Association, 2021. This paper is not the copy of record and may not exactly replicate the authoritative document published in the APA journal. Please do not copy or cite without author's permission.

longitudinal studies) to examine the interaction between self-criticism and emotion regulation strategies. By examining between- as well as within-individual associations over time, the present study contributes to the understanding of how these transdiagnostic risk factors interact with one another over time. We examined six emotion regulation strategies: three emotion regulation strategies in response to negative affect, and three in response to positive affect.

In response to negative affect we examined rumination, which consists of repeatedly dwelling on a negative emotion or event (Abela \& Hankin, 2011; Aldao et al, 2010; Hoff \& Muehlenkamp, 2009; McLaughlin, Hatzenbuehler, Mennin \& Nolen-Hoeksema, 2011; Nolen-Hoeksema, Stice, Wade, \& Bohon, 2007; Schäfer, Naumann, Holmes, TuschenCaffier \& Samson, 2017), problem-solving, which refers to individuals' conscious attempts to resolve distress by changing the situation (Aldao et al, 2010; Becker-Weidman, Jacobs, Reinecke, Silva, March, 2010; Bell \& D’Zurilla, 2009; Schäfer et al, 2017; Siu \& Shek, 2010), and distraction, which refers to diverting one's attention away from the stimulus causing distress to something else (Abela, Aydin \& Auerbach, 2007; Compas et al, 2017; Webb, Miles \& Sheeran, 2012).

In response to positive affect, we examined dampening, which refers to downgrading the significance of a positive event (Gentzler, Morey, Palmer \& Yuen Yi, 2013; Gilbert, Luking, Pagliaccio, Luby \& Barch, 2017; Gomez-Baya, Mendoza, Paino \& Gillham, 2017; Nelis et al., 2016), emotion-focused positive rumination, which refers to focusing on the emotional sensations experienced in that positive mood state (Bijttebier, Raes, Vasey \& Feldman, 2012; Feldman, Joormann \& Johnson, 2008; Gilbert et al, 2017; Shapero et al., 2015; Verstraeten, Vasey, Raes \& Bijttebier, 2012), and self-focused positive rumination, which refers to the attribution of positive affect to one's own positive qualities or personal 
CAmerican Psychological Association, 2021. This paper is not the copy of record and may not exactly replicate the authoritative document published in the APA journal. Please do not copy or cite without author's permission.

goal achievement (Bijttebier et al, 2012; Feldman et al, 2008; Gilbert et al, 2017; Gilbert,

Nolen-Hoeksema, \& Gruber, 2013; Gomez-Baya, Mendoza, Paino \& Gillham, 2017; Nelis et al, 2016). Positive ruminations are also known as savoring in the emotion regulation literature (Bryant, 2003; Li, Starr, Hershenberg, 2017; Martin \& Tesser, 1996; Quoidbach, Berry, Hansenne, \& Mikolajczak, 2010; Wood, Heimpel, \& Michela, 2003).

The present study was exploratory in nature; given the dearth of previous literature that conducted similar analyses, our hypotheses are broad and do not include all possible associations that are examined in our analyses.

We hypothesized that (1) emotion regulation strategis would be correlated across all levels of analysis (i.e., between and within subjects, as well as across time), given the significant associations demonstrated between emotion regulation strategies (McMahon \& Naragon-Gainey, 2018; Naragon-Gainey et al, 2017). Specifically, we hypothesized that strategies focusing on negative mood (rumination, distraction, and problem-solving) would be closely associated with one another, forming a network while strategies focusing on positive mood (dampening, emotion-focused and self-focused positive rumination) would form sub-clusters (i.e., would be clustered closer together). (2) We hypothesized that selfcriticism would be most closely tied to emotion regulation strategies that putatively act as risk factors for psychopathology, particularly rumination and dampening. Since depressive symptoms are highly associated with both self-criticism and emotion regulation strategies (e.g., Ehret, Joormann \& Berking, 2014; Bakker, Cox, Hubley \& Owens, 2019), we conducted all the analyses with and without depressive symptoms in the model, to be able to rule it out as an alternative explanation. 
CAmerican Psychological Association, 2021. This paper is not the copy of record and may not exactly replicate the authoritative document published in the APA journal. Please do not copy or cite without author's permission.

\section{Participants}

All procedures have been approved by Yale University Institutional Review Board. One-hundred and forty-eight children and adolescence were recruited via flyers in the university area, Craigslist, and on social media. Ads invited 9-15 years old children and adolescence to participate in a daily-diary study about emotions and social experiences. Participants were eligible if they were within the age range and had daily access to a device connected to the internet. Participants received $\$ 40$ if they completed $60 \%$ of surveys and $\$ 60$ if they completed at least $90 \%$. Thirteen participants were excluded; Ten completed fewer than $60 \%$ of the diary entries, and three participants had more than a third of the diary days with zero variance in the mood items. The final sample included 135 children and adolescence (91\% of the original sample; 70 girls). Mean age was 11.85 (range 8-15 since we allowed children who would have turned 9 during the diary period to participate). Table 1 presents demographics according to gender.

Power analysis. The present study is part of a larger project on emotions and social interactions. Sample size was determined with a power analysis conducted using PASS software (https://www.ncss.com/software/pass), based on data from the first 18 participants and adjusting for intra-class correlations. According to the power analysis, we needed a sample of 120 participants assuming $80 \%$ power and a two-sided $\alpha$ of 0.05 to detect main effects of interest in the larger study. We continued with data collection until 120 participants completed at least $60 \%$ of their daily diaries.

\section{Procedure}

Participants came to the lab for an initial visit with a parent. During the visit, a research assistant reviewed the diary questions to ensure participants understood the questions and felt comfortable answering them. Participants signed assent forms and their 
CAmerican Psychological Association, 2021. This paper is not the copy of record and may not exactly replicate the authoritative document published in the APA journal. Please do not copy or cite without author's permission.

parents signed consent forms. Then, participants completed a practice survey and a demographics questionnaire on a lab computer. Every evening for 21 days, participants received a link via email to the daily survey which they completed on a secure website (Qualtrics). Although participants were instructed to complete the survey before going to bed, the link expired after 14 hours, allowing them to complete questionnaires the following morning if needed. All the data was collected between 1/31/2019 and 9/23/2019, therefore spanning both school year and summer months.

\section{Measures}

The present study is part of a larger study on emotions and social experiences in children and adolescence; only relevant measures are described. All study materials are available online osf.io/p6hwv.

Regulation of negative mood. To assess regulation of negative mood we adapted six items from the Children's Response Style Questionnaire (CRSQ; Abela, Rochon \& Vanderbilt, 2000). The CRSQ is a self-report questionnaire used to assess three strategies for regulating negative mood at the trait level: problem-solving (e.g., "I talked it out with someone I think can help me feel better"), distraction (e.g., "I did something I enjoy"), and rumination (e.g., "I thought about: "I'm ruining everything"”). Two items were used to assess each strategy. Items were rated on 5-point scales, ranging from 0 ("irrelevant - was not in a bad mood") to 4 ("almost all of the time"). Instructions and items were adapted for dailydiary in two ways. First, instead of asking participants if they used a strategy when they were sad (without limitation of time frame), we asked participants if they had used this strategy when they were in a bad mood, and specified the time frame from between the previous night to right now (i.e., in the last 24 hours). We chose to ask about "bad mood" instead of a specific emotion (sadness) because of the significant variability and changes in the ability to 
CAmerican Psychological Association, 2021. This paper is not the copy of record and may not exactly replicate the authoritative document published in the APA journal. Please do not copy or cite without author's permission.

recognize and verbalize specific emotions in this age range (Nook et al., 2017, 2018, 2020).

Second, we altered the response scale and added a response option indicating that the strategy was not used in the last day, thus making it more appropriate to capture state-level constructs (vs. the original questionnaire that aims to capture trait-level constructs).

We calculated the between- and within-subject reliabilities using procedures outlined in Shrout and Lane (2012). For a given measure, the between-person reliability coefficient is the expected between-person reliability estimate for a single typical day. The within-subject reliability coefficient is the expected within-subject reliability of change within individuals over the daily-diary period. The between-person and within-person reliabilities were .68 and .60 for rumination, .69 and .54 for distraction, and .77 and .45 for problem-solving. These reliabilities are considered acceptable for within-individual measures, since in intensive longitudinal design we expect constructs to fluctuate over time; this is in contrast to trait-level variability that assumes consistency (Shrout, 1998; Nezlek, 2017).

Regulation of positive mood. To assess regulation of positive mood, we adapted seven items from the Responses to Positive Affect Questionnaire for Children (RPA-C; Bijttebier, Raes, Vasey, \& Feldman, 2012). The RPA-C is a self-report questionnaire assessing three strategies for regulating positive mood at the trait level: Emotion-focused positive rumination (e.g., "Notice how you feel full of energy"), Self-focused positive rumination (e.g., "Think 'I am the best I could be'”), and Dampening (e.g., "Think 'I don't deserve this"'). We used three items to assess emotion-focused positive rumination, and two items to assess each of the other scales. Items were rated on 5-point scales, ranging from 0 ("irrelevant - was not in a good mood") to 4 ("almost all of the time”). Instructions and items were similar to those for regulation of negative mood. Similarly, instead of asking participants to report which emotion regulation strategies they used when they are happy, we 
CAmerican Psychological Association, 2021. This paper is not the copy of record and may not exactly replicate the authoritative document published in the APA journal. Please do not copy or cite without author's permission.

asked about positive mood. The between-person and within-person reliabilities ranged between fair to moderate (Shrout, 1998; Nezlek, 2017): .84 and .62 for emotion-focused positive rumination, .82 and .46 for self-focused positive rumination, and .66 and .41 for dampening. These reliabilities are considered acceptable for within-individual measures (Shrout, 1998; Nezlek, 2017).

Self-criticism. To assess self-criticism, we adapted three items (as recommended Shrout \& Lane, 2011) from the Self-Rating Scale (SRS; Hooley et al, 2010), a self-report questionnaire assessing self-criticism. Instructions were adapted for use of daily diary by asking participants to rate the extent to which they were currently experiencing self-criticism right now, whereas in the original questionnaire no timeframe is given. The wording in one of the items was modified to be more suitable for children and adolescence ("I often feel inferior to others" was replaced by "I am worth less than other people", since the word "inferior" requires a readability level expected only from our older participants), but the other two items were identical to the original questionnaire. We also made a change to the response scale: the original scale ranges from 1 to 7 , but we chose to have the scale range only from 1 ("very slightly or not at all") to 5 ("extremely"). This change was done to reduce participant burden as all other items in the section of the questionnaire were rated on that scale. The betweenperson and within-person reliabilities were .84 and .64 . These reliabilities are considered acceptable for within-individual measures (Shrout, 1998; Nezlek, 2017).

Depressive Symptoms. To assess depressive symptoms, we used the Children's Depression Inventory - short version (CDI-S; Kovacs, 1985). The CDI-S is a self-report measure consisting of 10 items used to assess severity of depressive symptoms. The short forms similar to the full measure in its specificity and sensitivity to screen for depression in children (Allgaier et al, 2012). Each item consists of three sentences representing different 
CAmerican Psychological Association, 2021. This paper is not the copy of record and may not exactly replicate the authoritative document published in the APA journal. Please do not copy or cite without author's permission.

degrees of symptom severity (from 0 to 2 ), from which the participant needs to choose the ones that describes them best. Instructions were adapted for use of daily-diary by asking participants to choose from each group of sentences the sentence that describes them best in the moment of answering the survey. The between-person and within-person reliabilities were .91 and .75 . These reliabilities are considered good for within-individual measures (Shrout, 1998; Nezlek, 2017). In the present sample, mean of depressive symptoms was 2.68 $(S D=3.04$, range 0-14.94). The score suggested as the clinical cutoff for the short version is a score $\geq 3$; thus, $34 \%$ of our participants met this criterion. It should be noted that this ratio of clinical levels of depressive symptoms is higher than previously-reported for participants within this age range, although prior investigations used trait-level measures rather than daily diary (Salk et al., 2016).

\section{Compliance}

On average, participants responded to 19 of the 21 daily diary surveys ( $S D=2$; range: 13-21 days); this resulted in 2564 assessment occasions across participants. Sensitivity analyses indicated that demographic characteristics (age, gender, race), emotion regulation strategy use (rumination, distraction, problem solving, dampening, emotion-focused positive rumination, self-focused positive rumination), and self-criticism did not significantly predict the number of completed daily diary surveys at $p<.05$.

\section{Statistical analyses}

All analyses were conducted using R 3.6.3 (R Core Team, 2018). The multivariate time-series data was analyzed using a network approach based on the multilevel vectorautoregression (mlVAR) model (Bringmann et al, 2013), as implemented in R-package mlVAR (Epskamp, Deserno, \& Bringmann, 2019). The mlVAR package estimates temporal, contemporaneous, and between-subjects network using all the data from relevant study 
CAmerican Psychological Association, 2021. This paper is not the copy of record and may not exactly replicate the authoritative document published in the APA journal. Please do not copy or cite without author's permission.

variables at the different measurement occasions. The contemporaneous network represents within-subject relations between the variables within the same time point. These relations reflect partial correlations after controlling for all other variables at the same time point and temporal relations between the variables. The temporal network represents within-subject lag-1 (i.e., previous time-point) relations between the variables and represents how a variable is predicted by all other variables in the network at a previous time point. These lag-1 relations represent partial correlations between variables because they control for all other temporal relations in the network. It should be noted that lagged entries were included in analysis if they were less than 39 hours from the current entry. We chose 39 hours since two consecutive diary entries could have been 24-38 hours apart (since the diary link was active for 14 hours after sending). Finally, the between-person network represents the pairwise correlations between the mean-levels of the variables across all days. These pairwise correlations control for all the other variables in the network and thus reflect partial correlations between mean levels of the variables in the network. These three networks are estimated via a two-step procedure. The first step fits a series of multilevel models (one for each variable in the network) in which a variable measure at time $t$ is predicted by all withinperson centered variables (including itself) measured at time $t-1$. This provides estimates of the temporal effects (provided by the slopes) and person-specific means (provided by the intercepts) to estimate between-person correlations. The second step estimates contemporaneous correlations using the residuals from the models fitted in the first step. It is then tested how the residuals of one variable are predicted by the residuals of all other variables at the same time point.

To investigate the relation between self-criticism and emotion regulation, the mIVAR analyses included self-criticism, and the use of various emotion regulation strategies (i.e., 
CAmerican Psychological Association, 2021. This paper is not the copy of record and may not exactly replicate the authoritative document published in the APA journal. Please do not copy or cite without author's permission.

rumination, distraction, problem solving, dampening, emotion-focused positive rumination, self-focused positive rumination). Since depressive symptoms are highly correlated with selfcriticism and emotion regulation (Burwell, 2015), we also run all the models including depressive symptoms in the model to rule out alternative explanations; Figures S1-S3 in the supplementary materials present models with depressive symptoms. The networks were visualized using the R-package qgraph (Epskamp, Cramer, Waldorp, Schmittmann, \& Borsboom, 2012). In the graphs, the study variables are represented as nodes and the relations between the nodes as edges. Node position was determined by the Fruchterman and Reingold (1991) algorithm, positioning nodes closer to the center of the graph when they have stronger connections with other nodes in the network. In the figures below, green lines represent positive associations and red lines represent negative associations. The thickness and shading of the edges reflects the magnitude of the association (thicker and darker edges reflect stronger associations). Only significant edges are plotted in the visualized networks, including the coefficients denoting the strength of the association.

In line with prior work (e.g., Aalbers, McNally, Heeren, de Wit, \& Fried, 2019), the Kwiatkowksi-Phillips-Schmidt-Shin (KPSS) unit root tests examined the stationary assumption in individual time series for each study variable. The KPSS tests indicated that the stationary assumption was met for all participants and study variables.

\section{Results}

\section{Preliminary analyses}

Table 2 displays means, SDs, and intraclass correlation coefficients (ICCs) for all study variables. The ICC values indicate that there was considerable variability at both the between-person and within-person level for each study variable. 
CAmerican Psychological Association, 2021. This paper is not the copy of record and may not exactly replicate the authoritative document published in the APA journal. Please do not copy or cite without author's permission.

\section{Network models}

The contemporaneous network (see Figure 1) revealed two clusters of emotion regulation strategies that tended to co-occur on a given day. In a first cluster, positive partial correlations emerged among emotion regulation strategies that serve to regulate positive emotional experiences. On a given day, participants tended to regulate their positive emotions through dampening as well as both emotion-focused and self-focused forms of positive rumination. In a second cluster, positive correlations occurred among negative emotion regulation strategies. This suggests that, on a given day, persons reporting higher levels of rumination also engaged more in problem-solving and distraction to regulate negative affect.

Interestingly, self-criticism connected the clusters of positive and negative emotion regulation strategies. Self-criticism was positively related to both dampening and rumination. Thus, on a given day, persons reporting higher levels of self-criticism also engaged in rumination and dampening. Furthermore, there were direct connections between the clusters of emotion regulation strategies. In particular, emotion-focused rumination was positively related to distraction. As can be seen in Figure S1, this pattern did not change when daily depressive symptoms were entered to the model.

The temporal network (see Figure 2) showed self-criticism uniquely predicted both rumination and dampening on the next day. Higher levels of self-criticism were related to subsequent increases in rumination but decreases in dampening. Furthermore, problem solving was related to higher levels of both dampening and rumination on the following day. Also, distraction predicted greater self-focused positive rumination on the next day. Selffocused positive rumination in turn predicted subsequent increases in emotion-focused positive rumination. Finally, self-criticism, problem-solving, dampening, distraction, and self-focused positive rumination had positive auto-regression effects. This suggests that these 
CAmerican Psychological Association, 2021. This paper is not the copy of record and may not exactly replicate the authoritative document published in the APA journal. Please do not copy or cite without author's permission.

factors tended to persist over time. As can be seen in Figure S2, this pattern did not change when daily depressive symptoms were entered to the model.

Finally, the between-person network (see Figure 3) showed that emotion regulation strategies in response to negative emotions clustered together. Across participants, higher levels of rumination were related to higher levels of both distraction and problem-solving. Moreover, the purported adaptive strategies (distraction and problem-solving) were related to emotion-focused and self-focused positive rumination. By contrast, rumination was related to higher levels of dampening of positive emotions and self-criticism. Dampening and selfcriticism were also positively related. As can be seen in Figure S3, this pattern did not change when daily depressive symptoms were entered to the model.

\section{Discussion}

The present study is the first to investigate inter-relations of two important transdiagnostic risk factors of psychopathology in adolescents, self-criticism and emotion regulation, using network analysis in an intensive longitudinal design. Our results show that self-criticism and emotion regulation strategies are inter-related, and that the pattern of interrelation is different in the between-person, contemporaneous, and temporal networks. Four major findings emerged from our analyses.

First, as predicted, emotion regulation strategies were more strongly and positively interconnected with one another, with sub-clusters according to target emotion appearing in the contemporaneous network, and clustering according to putative adaptiveness in the between-person network. However, the temporal network revealed a different picture as detailed below. Second, unexpectedly, problem-solving in response to negative affect, which is typically considered a protective factor (Aldao et al, 2010), was closely related to 
CAmerican Psychological Association, 2021. This paper is not the copy of record and may not exactly replicate the authoritative document published in the APA journal. Please do not copy or cite without author's permission.

rumination, and to a lesser degree also to dampening in the within- and between-person networks. Moreover, the temporal network showed that problem-solving was related to nextday increases in use of rumination and dampening. Third, partially supporting our hypothesis, self-criticism was positively associated with rumination and dampening in the betweenperson and contemporaneous networks and predicted next-day increases in rumination in the temporal network. Surprisingly, it predicted next-day decreases in dampening as well. Lastly, distraction in response to negative affect, though clustering with other strategies focusing on negative affect in the between-person and contemporaneous networks, was also closely related to the two types of positive rumination which typically are related to the upregulation of positive affect. Moreover, the temporal network showed use in distraction was related only to increases in positive ruminations. All findings held when depressive symptoms were entered into the networks.

\section{(1) Emotion Regulation Strategies are Inter-connected}

The results from the contemporaneous network support our hypothesis that strategies in response to negative affect (rumination, distraction, problem-solving) and strategies in response to positive affect (dampening, emotion-focused positive rumination, self-focused positive rumination) form sub-clusters, likely because they are activated in response to the same emotional target. Indeed, the contemporaneous network showed that when examining emotion regulation strategies on the same day, two main clusters of emotion regulation strategies emerged: emotion regulation strategies that regulate positive emotions and strategies that regulate negative emotions. This finding suggests that on days when children and adolescence regulated their negative or positive affect, they did so using several strategies, not just one. This finding is in line with previous findings in adults (Heiy \& Cheavens, 2014; McMahon \& Naragon-Gainey, 2018) and with the idea of "poly-regulation" 
CAmerican Psychological Association, 2021. This paper is not the copy of record and may not exactly replicate the authoritative document published in the APA journal. Please do not copy or cite without author's permission.

or the simultaneous use of multiple emotion regulation strategies (Ford et al., 2019). These findings extend previous results from adults to children and adolescence, and by using network analysis, a novel approach to assess poly-regulation in children and adolescence. Additionally, these results extend prior studies by investigating the interaction of emotion regulation strategies in response to both positive and negative affect together with selfcriticism. Interestingly, in the between-person and temporal networks, emotion regulation strategies did not cluster according to target affect, as discussed below.

\section{(2) Problem Solving is Closely Related to Putatively Maladaptive Emotion-}

\section{Regulation Strategies ${ }^{1}$}

Problem-solving in response to negative mood is generally considered adaptive (Aldao et al, 2010; Schäfer, Naumann, Holmes, Tuschen-Caffier, \& Samson, 2016). However, our findings suggest that we may need to inspect this emotion-regulation strategy more carefully. In the between-person network, our results were very much in line with previous literature showing the adaptiveness of problem-solving: it was positively associated with other strategies focusing on negative affect (i.e., rumination and distraction) and with self-focused positive rumination. This finding shows that individuals that tend to regulate their negative affect do it using all strategies - and that specifically people who use problemsolving also use self-focused positive rumination, a putatively adaptive strategy (Nelis et al., 2018) to regulate their positive affect. However, findings from the contemporaneous network began to diverge from this common interpretation - showing that problem-solving is clustered with other strategies focusing on negative affect, but surprisingly is also positively associated with dampening, a putatively maladaptive strategy focusing on positive affect. Moreover, the temporal network unexpectedly revealed that problem-solving is related to an

\footnotetext{
${ }^{1}$ We thank the anonymous reviewer for their insightful comments on this section
} 
CAmerican Psychological Association, 2021. This paper is not the copy of record and may not exactly replicate the authoritative document published in the APA journal. Please do not copy or cite without author's permission.

increase in rumination and dampening on the next day. Thus, it appears that the attempt to solve problems in response to negative moods can backfire.

There are several possible explanations for this finding. First, this finding regarding the potentially risk-enhancing aspects of problem solving is reminiscent of studies examining reflection. Reflection is defined as attempts to understand the causes for one's negative moods and was originally considered an emotion regulation strategy that decreases risk for psychopathology (Miranda \& Nolen-Hoeksema, 2007; Treynor et al, 2003). However, studies on adults have shown that reflection can lead to increased engagement in rumination one year later (Miranda \& Nolen-Hoeksema, 2007; Treynor et al, 2003). Although reflection and problem-solving are distinct processes, they both include focusing on the problem (Aldao \& Nolen-Hoeksema, 2010; Billings \& Moos, 1981). In other words, perhaps by increasing focus on the problem, problem-solving encouraged a mindset that considers negative aspects - thus facilitating strategies that are characterized by focus on the negative, namely rumination and dampening.

A second explanation to this finding may result from the way in which problemsolving was executed. For example was the problem thought about in an abstract manner, or a concrete one? It is possible that our participants used more abstract thinking (vs. concrete; Watkins \& Roberts, 2020), or were simply ineffective in their attempts to problem solve, which may then lead to rumination, and dampening. Thus, it is possible that this association results from failed attempts to problem-solve that "turned into" rumination and dampening. Indeed, the items we used to assess problem solving show some overlap with the corumination questionnaire (Davidson et al., 2014). Further studies looking more closely at these constructs are needed to better understand these associations. 
CAmerican Psychological Association, 2021. This paper is not the copy of record and may not exactly replicate the authoritative document published in the APA journal. Please do not copy or cite without author's permission.

A third explanation for these findings may be related to the need to examine problemsolving in a more fine-grained way. For example, it is likely that problem-solving focused on uncontrollable problems would be ineffective and may increase distress (Hayes et al., 2006; Lazarus, 1985), whereas problem-solving focused on a solvable problem, would be effective. This direction of investigation is in line with growing literature that suggests that emotion regulation strategies that were traditionally considered as adaptive may lead to adverse outcomes under certain conditions (Bonanno \& Burton, 2013; Sheppes, 2020). However, most of this literature focused on reappraisal; the present investigation extends this line of research to include problem-solving. Overall, these findings call for a more nuanced categorization of emotion regulation strategies rather than the current categorization as either maladaptive or adaptive. Additionally, these findings have important implications for treatment, as it appears that even an active approach to solving one's problems may increase negative mood and may lead to use of emotion regulation strategies that increase risk for psychopathology.

(3) The "Dark Triad" of Risk Factors? Self-criticism, Rumination, and Dampening

As predicted and previously found (Grommisch et al., 2020; McMahon \& NaragonGainey, 2018), the between-person network showed strong associations among all risk factors - namely self-criticism, rumination, and dampening. These findings suggest that individuals who are more critical of themselves, also tend to look at the negative aspects of both positive and negative affect, forming a triad of risk factors. This triad was found, albeit with weaker associations, also in the contemporaneous network, showing that on days in which individuals were more self-critical, they also used more rumination and dampening. The temporal network sheds further light on this process - on days following self-criticism, children and adolescence ruminated. These findings in line with literature suggesting that the 
CAmerican Psychological Association, 2021. This paper is not the copy of record and may not exactly replicate the authoritative document published in the APA journal. Please do not copy or cite without author's permission.

direction of association between self-criticism and rumination is mostly from self-criticism to rumination (Bernstein et al., 2017) as well as with theoretical conceptualization of selfcriticism (e.g., Shahar, Rogers, Shalev, \& Joiner, 2020). However, to our surprise, selfcriticism was related to next-day decreases in dampening. Future studies are needed to further understand the temporal associations between self-criticism and dampening.

(4) A Positive Triad of Emotion Regulation? Distraction and Positive Rumination

\section{Strategies}

As predicted, distraction in response to negative affect was closely related to other strategies focusing on negative affect both at the between-person and contemporaneous networks. These results are in line with previous findings (Grommisch et al., 2019) showing that individuals differ in the degree to which they regulate their negative affect (i.e., some regulate often, and some rarely, using a variety of strategies), and not necessarily in the specific strategies they use. Interestingly, individuals who distract more also tend to dampen their positive affect less - this is not surprising since distraction by focusing on positive things (as we assessed it) is indeed the opposite of dampening that directs attention to the negative side of things. Moreover, in the contemporaneous network - distraction was associated not only with strategies focusing on negative affect, but also with lower levels of self-criticism and higher levels of emotion-focused positive rumination. Thus, on days in which people distracted themselves more they were also less self-critical and used strategies that upregulate positive affect - suggesting that (at least some types of) distraction incurs benefits beyond the intended down-regulation of negative affect.

Indeed, the temporal network revealed that on days after children and adolescence used distraction, they used more self-focused positive rumination, which in turn predicted more emotion-focused positive rumination. These findings elucidate the ways in which 
CAmerican Psychological Association, 2021. This paper is not the copy of record and may not exactly replicate the authoritative document published in the APA journal. Please do not copy or cite without author's permission.

distraction in response to negative affect may be followed by positive affect, by triggering emotion regulation strategies that enhance positive affect - forming a positive triad of emotion regulation strategies. Thus, it is likely that distraction increased positive affect, which led to its upregulation. Similarly, studies have demonstrated that distraction is significantly associated with increases in positive affect (e.g., Brans, Koval, Verduyn, \& Lim, 2013). This could explain findings that show distraction significantly modulated negative affect in high-intensity situations (Shafir, Schwartz, Blechert, \& Sheppes, 2015; Sheppes, Brady, \& Samson, 2014; Sheppes \& Meiran, 2007; Sheppes, Suri, \& Gross, 2015). It should be noted that our distraction items included exclusively distraction via focusing on something positive. Future research should assess other types of distraction -- e.g., distraction by focusing on activities that are not necessarily positive or "fun", such as doing chores, homework, or engaging in sports. This will help uncover the different or similar underlying "chain reaction" processes by which distraction modulates different types of affect.

\section{Strengths and Limitations}

The present study is the first to employ network analyses to understand the interconnection of self-criticism and emotion regulation strategies. Network analysis treats variables as interactive and examines the patterns of interconnection between them (Borsboom \& Cramer, 2013; Cramer, Waldorp, van der Maas \& Borsboom, 2010; Lee et al, 2020). Given that most of the literature investigates how emotion regulation factors interact with symptoms of psychopathology by assessing only one emotion regulation strategy and/or emotion regulation factors, these findings address an important gap in the literature on how these factors unfold and interact naturalistically. Importantly, the results from our temporal network sheds unique light on how risk factors unfold over time. 
CAmerican Psychological Association, 2021. This paper is not the copy of record and may not exactly replicate the authoritative document published in the APA journal. Please do not copy or cite without author's permission.

This study has limitations that should be acknowledged. Our main limitation is that we assessed our variables only once a day. Since we do not know the temporal resolution in which the processes in question unfold, this issue limits our temporal networks in particular. Higher temporal resolution of assessments is needed to better capture how risk factors interact during the day. Relatedly, the measures we used were not designed to assess state constructs, and the adaptations we made to them may have compromised their validity. In addition, we used only two items to assess each emotion regulation strategy, whereas the recommendation is to use three (Shrout \& Lane, 2011); this resulted in low (though acceptable) reliability, which decreased our power to detect effects and may have impacted the network edges (i.e., the associations between the variables). Future studies should adhere to these guidelines. Another limitation is our reliance on a community sample. This limits the generalizability of these patterns to clinical samples. Although the network structure yielded the same results when depressive symptoms were included in the model, future research should investigate whether these present findings replicate for different psychopathologies in adolescence, by comparing network structures of adolescents with and without psychopathology. Importantly, the inclusion of depression in the temporal model showed that none of the risk factors predicted next-day depression; this could be because of our temporal resolution or because depression was entered as a sum of all symptoms, thus obscuring important temporal associations. However, the current investigation focused on the associations between risk factors; future studies following up on these analyses are needed. Similarly, future studies could compare network structures for adolescents under stressful conditions such as COVID-19 or exam period at school, to see if and how networks change under stress. Finally, since the present study - although longitudinal - did not use an 
CAmerican Psychological Association, 2021. This paper is not the copy of record and may not exactly replicate the authoritative document published in the APA journal. Please do not copy or cite without author's permission.

experimental design, no conclusions about causality can be made; for example, third variables may have contributed to the associations we found.

\section{Future Directions}

The current study is one of the first steps taken in the study of emotion polyregulation using network analysis. One of the ways in which the current study adds to the literature is its focus on a developmental period that has been understudied from the perspective of poly-regulation of emotions (cf. van den Huevel et al., 2020), but it is only a first step in this direction. Children and adolescence go through dramatic social and emotional changes in the age range we included (Rappee et al., 2019). Future longitudinal studies are needed to examine if and how network structure changes from childhood to adulthood, and the possible role of this interconnected structure in the high comorbidity rates we see in children and adolescents (vs. adults; Kessler, Chiu, Demler \& Walters, 2005; Melton, Croarkin, Strawn \& Mcclintock, 2016). Another important direction for future research arises from the complexity of our (and other's; Grommisch et al., 2020; McMahon \& Naragon-Gainey, 2018) results when examining polyregulation. Though it is highly important to understand this phenomenon in a fine-grained way, the literature could also benefit from a metric that summarizes this complexity in a useful way (e.g., network density; Shin et al., 2021). Finally, the current study examined only six emotion regulation strategies and one additional risk factor; additional research is needed to examine how other emotion regulation strategies (e.g., reappraisal, acceptance) and other risk factors (e.g., perceived social support) add to the networks, thus helping us achieve a more comprehensive understanding of risk and resilience.

\section{Clinical implications}


CAmerican Psychological Association, 2021. This paper is not the copy of record and may not exactly replicate the authoritative document published in the APA journal. Please do not copy or cite without author's permission.

The results of the present study could inform interventions and treatments. In particular, our temporal network suggests two important directions for intervention: encouraging children and adolescents to use distraction by focusing on positive activities may create a positive spiral. Alternatively, the specific combination of self-criticism and problem solving can lead to increased risk. Thus, focusing on decreasing self-criticism and adopting effective ways to problem solve could be beneficial.

\section{Summary}

The current study is a unique investigation of how risk and protective factors interact over time in a sample of children and adolescents, using network analysis. Our study is innovative in its examination of the contemporaneous, temporal and between-person networks of emotion regulation. These findings are particularly robust given that the associations among emotion regulation strategies held even when controlling for depression. Our findings suggest that risk factors interact as a dynamic and interconnected system, some forming vicious or benevolent cycles. As a result, these findings elucidate the pathways by which risk factors unfold. Importantly, our results show how important it is to separate not only trait-level from state-level findings but also contemporaneous from temporal associations, as each level of analyses shed different light on the associations between risk factors. Overall, these findings have important theoretical implications for studying risk factors as highly transdiagnostic and interactive processes. Given these innovative findings about the interconnected nature of risk factor processes, more research is needed to understand how these processes unfold in the context of adolescent development and how this may explain why there is stronger comorbidity observed in adolescents. 
CAmerican Psychological Association, 2021. This paper is not the copy of record and may not exactly replicate the authoritative document published in the APA journal.

Please do not copy or cite without author's permission.

\section{References}

Aalbers, G., McNally, R. J., Heeren, A., de Wit, S., \& Fried, E. I. (2019). Social media and depression symptoms: A network perspective. Journal of Experimental Psychology: General, 148(8), 1454-1462. https://doi.org/10.1037/xge0000528

Abela, J. R. Z., \& Hankin, B. L. (2011). Rumination as a vulnerability factor to depression during the transition from early to middle adolescence: A multiwave longitudinal study. Journal of Abnormal Psychology, 120(2), 259-

271. https://doi.org/10.1037/a0022796

Abela, J. R. Z., Aydin, C. M., \& Auerbach, R. P. (2007). Responses to depression in children: Reconceptualizing the relation among response styles. Journal of Abnormal Child Psychology, 35(6), 913-927. https://doi.org/10.1007/s10802-007-9143-2

Abela, J. R. Z., Rochon, A., \& Vanderbilt, E. (2000). The Children's Response Style Questionnaire (Unpublished questionnaire). Montreal, Canada: McGill University.

Aldao, A., \& Nolen-Hoeksema, S. (2010). Specificity of cognitive emotion regulation strategies: A transdiagnostic examination. Behaviour Research and Therapy, 48(10), 974-983. https://doi.org/10.1016/j.brat.2010.06.002

Aldao, A., \& Nolen-Hoeksema, S. (2012). The influence of context on the implementation of adaptive emotion regulation strategies. Behaviour Research and Therapy, 50(7-8), 493-501. https://doi.org/10.1016/j.brat.2012.04.004

Aldao, A., \& Nolen-Hoeksema, S. (2012). When are adaptive strategies most predictive of psychopathology? Journal of Abnormal Psychology, 121(1), 276281. https://doi.org/10.1037/a0023598

Aldao, A., Nolen-Hoeksema, S., \& Schweizer, S. (2010). Emotion-regulation strategies across psychopathology: A meta-analytic review. Clinical Psychology Review, 30(2), 
CAmerican Psychological Association, 2021. This paper is not the copy of record and may not exactly replicate the authoritative document published in the APA journal.

Please do not copy or cite without author's permission.

217-237.Allgaier, A. K., Pietsch, K., Frühe, B., Sigl-Glöckner, J., \& Schulte-Körne, G. (2012). Screening for depression in adolescents: validity of the patient health questionnaire in pediatric care. Depression and Anxiety, 29, 906-913. https://doi.org/10.1002/da.21971

Bakker, A. M., Cox, D. W., Hubley, A. M., \& Owens, R. L. (2019). Emotion regulation as a mediator of self-compassion and depressive symptoms in recurrent depression. Mindfulness, 10(6), 1169-1180. https://doi.org/10.1007/s12671-018-1072$\underline{3}$

Barendse, M. E., Cosme, D., Flournoy, J. C., Vijayakumar, N., Cheng, T. W., Allen, N. B., \& Pfeifer, J. H. (2020). Neural correlates of self-evaluation in relation to age and pubertal development in early adolescent girls. Developmental Cognitive Neuroscience, 44, 100799. https://doi.org/10.1016/j.dcn.2020.100799

Becht, A. I., Nelemans, S. A., Branje, S. J. T., Vollebergh, W. A. M., Koot, H. M., Denissen, J. J. A., \& Meeus, W. H. J. (2016). The quest for identity in adolescence:

Heterogeneity in daily identity formation and psychosocial adjustment across 5 years. Developmental Psychology, 52(12), 2010-2021. https://doi.org/10.1037/dev0000245

Becker-Weidman, E. G., Jacobs, R. H., Reinecke, M. A., Silva, S. G., \& March, J. S. (2010). Social problem-solving among adolescents treated for depression. Behaviour Research and Therapy, 48(1), 11-18. https://doi.org/10.1016/j.brat.2009.08.006

Bell, A. C., \& D'Zurilla, T. J. (2009). The influence of social problem-solving ability on the relationship between daily stress and adjustment. Cognitive Therapy and Research, 33(5), 439-448. https://doi.org/10.1007/s10608-009-9256-8 
CAmerican Psychological Association, 2021. This paper is not the copy of record and may not exactly replicate the authoritative document published in the APA journal.

Please do not copy or cite without author's permission.

Bernstein, E. E., Heeren, A., \& McNally, R. J. (2017). Unpacking rumination and executive control: A network perspective. Clinical Psychological Science, 5(5), 816826. https://doi.org/10.1177/2167702617702717

Bijttebier, P., Raes, F., Vasey, M. W., \& Feldman, G. C. (2012). Responses to positive affect predict mood symptoms in children under conditions of stress: A prospective study. Journal of Abnormal Child Psychology, 40(3), 381389. https://doi.org/10.1007/s10802-011-9579-2

Billings, A. G., \& Moos, R. H. (1981). The role of coping responses and social resources in attenuating the stress of life events. Journal of Behavioral Medicine, 4(2), 139-157.

Blatt, S. J., \& Zuroff, D. C. (1992). Interpersonal relatedness and self-definition: Two prototypes for depression. Clinical Psychology Review, 12(5), 527562. https://doi.org/10.1016/0272-7358(92)90070-O

Bonanno, G. A., \& Burton, C. L. (2013). Regulatory flexibility: An individual differences perspective on coping and emotion regulation. Perspectives on Psychological Science, 8(6), 591-612. https://doi.org/10.1177/1745691613504116

Borsboom, D., \& Cramer, A. O. J. (2013). Network analysis: An integrative approach to the structure of psychopathology. Annual Review of Clinical Psychology, 9, 91121. https://doi.org/10.1146/annurev-clinpsy-050212-185608

Brans, K., Koval, P., Verduyn, P., Lim, Y. L., \& Kuppens, P. (2013). The Regulation of Negative and Positive Affect in Daily Life. Emotion, 13(5), 926939. https://doi.org/10.1037/a0032400

Bringmann, L. F., Vissers, N., Wichers, M., Geschwind, N., Kuppens, P., Peeters, F., ... Tuerlinckx, F. (2013). A network approach to psychopathology: New insights into 
CAmerican Psychological Association, 2021. This paper is not the copy of record and may not exactly replicate the authoritative document published in the APA journal.

Please do not copy or cite without author's permission.

clinical longitudinal data. PLOS ONE, 8, https://doi.org/10.1371/journal.pone.0060188

Bryant, F. B. (2003). Savoring beliefs inventory (SBI): A scale for measuring beliefs about savouring. Journal of Mental Health, 12(2), 175-

196. https://doi.org/10.1080/0963823031000103489

Burwell, R. A. (2015). Self-evaluative and emotion processes linked with brooding rumination among adolescents. Journal of Adolescence, 41, 162-

174. https://doi.org/10.1016/j.adolescence.2015.03.007

Byrne, B. M., \& Shavelson, R. J. (1996). On the structure of social self-concept for pre-, early, and late adolescents: A test of the Shavelson, Hubner, and Stanton (1976) model. Journal of Personality and Social Psychology, 70(3), 599613. https://doi.org/10.1037/0022-3514.70.3.599

Casey, B. J., Duhoux, S., \& Cohen, M. M. (2010). Adolescence: what do transmission, transition, and translation have to do with it? Neuron, 67(5), 749-760. https://doi.org/10.1016/j.neuron.2010.08.033

Casey, B. J., Oliveri, M. E., \& Insel, T. (2014). A neurodevelopmental perspective on the research domain criteria (RDoC) framework. Biological Psychiatry, 76(5), 350-353. https://doi.org/10.1016/j.biopsych.2014.01.006

Compas, B. E., Jaser, S. S., Bettis, A. H., Watson, K. H., Gruhn, M. A., Dunbar, J. P., ... \& Thigpen, J. C. (2017). Coping, emotion regulation, and psychopathology in childhood and adolescence: A meta-analysis and narrative review. Psychological Bulletin, 143(9), 939-991. https://doi.org/10.1037/bul0000110 
CAmerican Psychological Association, 2021. This paper is not the copy of record and may not exactly replicate the authoritative document published in the APA journal.

Please do not copy or cite without author's permission.

Cramer, A. O. J., Waldorp, L. J., van der Maas, H. L. J., \& Borsboom, D. (2010).

Comorbidity: A network perspective. Behavioral and Brain Sciences, 33(2-3), 137-

150. https://doi.org/10.1017/S0140525X09991567

Davidson, C. L., Grant, D. M., Byrd-Craven, J., Mills, A. C., Judah, M. R., \& Lechner, W. V. (2014). Psychometric properties of the co-rumination questionnaire. Personality and Individual Differences, 70, 171-175. http://dx.doi.org/10.1016/j.paid.2014.07.002

Dixon-Gordon, K. L., Aldao, A., \& De Los Reyes, A. (2015). Emotion regulation in context: Examining the spontaneous use of strategies across emotional intensity and type of emotion. Personality and Individual Differences, 86, 271-

276. https://doi.org/10.1016/j.paid.2015.06.011

Ehret, A. M., Joormann, J., \& Berking, M. (2015). Examining risk and resilience factors for depression: The role of self-criticism and self-compassion. Cognition and Emotion, 29(8), 1496-1504. https://doi.org/10.1080/02699931.2014.992394

Eisenberg, N., Spinrad, T. L., \& Eggum, N. D. (2010). Emotion-related self-regulation and its relation to children's maladjustment. Annual Review of Clinical Psychology, 6, 495525. https://doi.org/10.1146/annurev.clinpsy.121208.131208

English, T., \& Eldesouky, L. (2020). Emotion regulation flexibility: Challenges and promise of using ecological momentary assessment. European Journal of Psychological Assessment, 36(3), 456-459. https://doi.org/10.1027/1015-5759/a000581

Epskamp, S., Cramer, A. O., Waldorp, L. J., Schmittmann, V. D., \& Borsboom, D. (2012). qgraph: Network visualizations of relationships in psychometric data. Journal of Statistical Software, 48(4), 1-18. DOI: 10.18637/jss.v048.i04 
CAmerican Psychological Association, 2021. This paper is not the copy of record and may not exactly replicate the authoritative document published in the APA journal.

Please do not copy or cite without author's permission.

Epskamp, S., Deserno, M. ., \& Bringmann, L. F. (2019). mlVAR: Multi-Level Vector

Autoregression. Retrieved February 6, 2020, from https://cran.r-

project.org/web/packages/mlVAR/index.html

Everaert, J., Bernstein, A., Joormann, J., \& Koster, E. H. (2020). Mapping dynamic interactions among cognitive biases in depression. Emotion Review, 12(2), 93-110.

Feldman, G. C., Joormann, J., \& Johnson, S. L. (2008). Responses to positive affect: A selfreport measure of rumination and dampening. Cognitive Therapy and Research, 32(4), 507-525. https://doi.org/10.1007/s10608-006-9083-0

Fennig, S., Hadas, A., Itzhaky, L., Roe, D., Apter, A., \& Shahar, G. (2008). Self-criticism is a key predictor of eating disorder dimensions among inpatient adolescent females. International Journal of Eating Disorders, 41(8), 762765. https://doi.org/10.1002/eat.20573

Flett, G. L., Coulter, L.-M., Hewitt, P. L., \& Nepon, T. (2011). Perfectionism, rumination, worry, and depressive symptoms in early adolescents. Canadian Journal of School Psychology, 26(3), 159-176. https://doi.org/10.1177/0829573511422039

Ford, B. Q., Gross, J. J., \& Gruber, J. (2019). Broadening our field of view: The role of emotion polyregulation. Emotion Review, 11(3), 197208. https://doi.org/10.1177/1754073919850314

Fruchterman, T. M., \& Reingold, E. M. (1991). Graph drawing by force-directed placement. Software: Practice and experience, 21(11), 1129-1164. https://doi.org/10.1002/spe.4380211102

Gentzler, A. L., Morey, J. N., Palmer, C. A., \& Yi, C. Y. (2013). Young adolescents' responses to positive events: Associations with positive affect and adjustment. The 
CAmerican Psychological Association, 2021. This paper is not the copy of record and may not exactly replicate the authoritative document published in the APA journal. Please do not copy or cite without author's permission.

Journal of Early Adolescence, 33(5), 663-

683. https://doi.org/10.1177/0272431612462629

Gilbert, K. E., Nolen-Hoeksema, S., \& Gruber, J. (2013). Positive emotion dysregulation across mood disorders: How amplifying versus dampening predicts emotional reactivity and illness course. Behaviour Research and Therapy, 51(11), 736-741. https://doi.org/10.1016/j.brat.2013.08.004

Gilbert, K., Luking, K., Pagliaccio, D., Luby, J., \& Barch, D. (2017). Dampening, Positive Rumination, and Positive Life Events: Associations with Depressive Symptoms in Children at Risk for Depression. Cognitive Therapy and Research, 41(1), 31-42. https://doi.org/10.1007/s10608-016-9798-5

Gomez-Baya, D., Mendoza, R., Paino, S., \& Gillham, J. E. (2017). A two-year longitudinal study of gender differences in responses to positive affect and depressive symptoms during middle adolescence. Journal of Adolescence, 56, 11-

23. https://doi.org/10.1016/j.adolescence.2017.01.005

Grommisch, G., Koval, P., Hinton, J. D., Gleeson, J., Hollenstein, T., Kuppens, P., \& Lischetzke, T. (2020). Modeling individual differences in emotion regulation repertoire in daily life with multilevel latent profile analysis. Emotion, 20(8), 14621474. https://doi.org/10.1037/emo0000669

Harter, S. (2015). The construction of the self: Developmental and sociocultural foundations( $2^{\text {nd }}$ ed.). New York, NY: Guilford Publications.

Hayes, S. C., Luoma, J. B., Bond, F. W., Masuda, A., \& Lillis, J. (2006). Acceptance and commitment therapy: Model, processes and outcomes. Behaviour Research and Therapy, 44(1), 1-25. https://doi.org/10.1016/j.brat.2005.06.006 
CAmerican Psychological Association, 2021. This paper is not the copy of record and may not exactly replicate the authoritative document published in the APA journal.

Please do not copy or cite without author's permission.

Heiy, J. E., \& Cheavens, J. S. (2014). Back to basics: A naturalistic assessment of the experience and regulation of emotion. Emotion, 14(5), 878891. https://doi.org/10.1037/a0037231

Hoff, E. R., \& Muehlenkamp, J. J. (2009). Nonsuicidal self-injury in college students: The role of perfectionism and rumination. Suicide and Life-Threatening Behavior, 39(6), 576-587. https://doi.org/10.1521/suli.2009.39.6.576

Hooley, J. M., Ho, D. T., Slater, J., \& Lockshin, A. (2010). Pain perception and nonsuicidal self-injury: A laboratory investigation. Personality Disorders: Theory, Research, and Treatment, 1(3), 170-179. DOI: 10.1037/a0020106

Hoorelbeke, K., Van den Bergh, N., Wichers, M., \& Koster, E. (2019). Between vulnerability and resilience: A network analysis of fluctuations in cognitive risk and protective factors following remission from depression. Behaviour Research and Therapy, 116, 1-9. https://doi.org/10.1016/j.brat.2019.01.007

Ingram, R. E., Miranda, J., \& Segal, Z. (2005). Cognitive Vulnerability to Depression. In L. B. Alloy \& J. H. Riskind (Eds.), Cognitive Vulnerability to Emotional Disorders $\left(1^{\text {st }}\right.$ ed., pp. 63-93). Lawrence Erlbaum Associates Publishers.

Joormann, J., Dkane, M., \& Gotlib, I. H. (2006). Adaptive and maladaptive components of rumination? Diagnostic specificity and relation to depressive biases. Behavior Therapy, 37(3), 269-280. https://doi.org/10.1016/j.beth.2006.01.002

Kessler, R. C., Chiu, W. T., Demler, O., \& Walters, E. E. (2005). Prevalence, Severity, and Comorbidity of 12-Month DSM-IV Disorders in the National Comorbidity Survey Replication. Archives of General Psychiatry, 62(6), 617-

627. https://doi.org/10.1001/archpsyc.62.6.617 
CAmerican Psychological Association, 2021. This paper is not the copy of record and may not exactly replicate the authoritative document published in the APA journal.

Please do not copy or cite without author's permission.

Klimstra, T. A., Hale III, W. W., Raaijmakers, Q. A., Branje, S. J., \& Meeus, W. H. (2010). Identity formation in adolescence: Change or stability? Journal of Youth and Adolescence, 39(2), 150-162. https://doi.org/10.1007/s10964-009-9401-4

Kolubinski, D. C., Nikčević, A. V., Lawrence, J. A., \& Spada, M. M. (2017). The metacognitions about self-critical rumination questionnaire. Journal of Affective Disorders, 220, 129-138. https://doi.org/10.1016/j.jad.2017.06.002

Kopala-Sibley, D. C., Zuroff, D. C., Hankin, B. L., \& Abela, J. R. Z. (2015). The development of self-criticism and dependency in early adolescence and their role in the development of depressive and anxiety symptoms. Personality and Social Psychology Bulletin, 41(8), 1094-1109. https://doi.org/10.1177/0146167215590985

Kopala-Sibley, D. C., Zuroff, D. C., Russell, J. J., \& Moskowitz, D. S. (2014). Understanding heterogeneity in social anxiety disorder: Dependency and self-criticism moderate fear responses to interpersonal cues. British Journal of Clinical Psychology, 53(2), 141156. https://doi.org/10.1111/bjc.12032

Lazarus, R. S. (1985). The Psychology of Stress and Coping. Issues in Mental Health Nursing, 7(1-4), 399-418. https://doi.org/10.3109/01612848509009463

Lee, J. S., Bainter, S. A., Carrico, A. W., Glynn, T. R., Rogers, B. G., Albright, C., ... \& Safren, S. A. (2020). Connecting the dots: a comparison of network analysis and exploratory factor analysis to examine psychosocial syndemic indicators among HIVnegative sexual minority men. Journal of Behavioral Medicine, 43(6), 1026-1040.

Lemogne, C., Delaveau, P., Freton, M., Guionnet, S., \& Fossati, P. (2012). Medial prefrontal cortex and the self in major depression. Journal of Affective Disorders, 136(1-2), e1e11. https://doi.org/10.1016/j.jad.2010.11.034 
CAmerican Psychological Association, 2021. This paper is not the copy of record and may not exactly replicate the authoritative document published in the APA journal. Please do not copy or cite without author's permission.

Li, Y. I., Starr, L. R., \& Hershenberg, R. (2017). Responses to positive affect in daily life: Positive rumination and dampening moderate the association between daily events and depressive symptoms. Journal of Psychopathology and Behavioral Assessment, 39(3), 412-425. https://doi.org/10.1007/s10862-017-9593-y

Martin, L. L., \& Tesser, A. (1996). Some ruminative thoughts. In R. S. Wyer, Jr. (Ed.), Advances in social cognition, Vol. 9. Ruminative thoughts (p. 1-47). Lawrence Erlbaum Associates, Inc.

McLaughlin, K. A., Hatzenbuehler, M. L., Mennin, D. S., \& Nolen-Hoeksema, S. (2011). Emotion dysregulation and adolescent psychopathology: A prospective study. Behaviour Research and Therapy, 49(9), 544554. https://doi.org/10.1016/j.brat.2011.06.003

McMahon, T. P., \& Naragon-Gainey, K. (2018). The moderating effect of maladaptive emotion regulation strategies on reappraisal: A daily diary study. Cognitive Therapy and Research, 42(5), 552-564. https://doi.org/10.1007/s10608-018-9913-x

Melton, T. H., Croarkin, P. E., Strawn, J. R., \& Mcclintock, S. M. (2016). Comorbid anxiety and depressive symptoms in children and adolescents: A systematic review and analysis. Journal of psychiatric practice, 22(2), 84-98.

\section{https://doi.org/10.1097/PRA.0000000000000132}

Mennin, D. S., Holaway, R. M., Fresco, D. M., Moore, M. T., \& Heimberg, R. G. (2007). Delineating components of emotion and its dysregulation in anxiety and mood psychopathology. Behavior Therapy, 38(3), 284-

302. https://doi.org/10.1016/j.beth.2006.09.001 
CAmerican Psychological Association, 2021. This paper is not the copy of record and may not exactly replicate the authoritative document published in the APA journal.

Please do not copy or cite without author's permission.

Miranda, R., \& Nolen-Hoeksema, S. (2007). Brooding and reflection: Rumination predicts suicidal ideation at 1-year follow-up in a community sample. Behaviour Research and Therapy, 45(12), 3088-3095. https://doi.org/10.1016/j.brat.2007.07.015

Naragon-Gainey, K., McMahon, T. P., \& Chacko, T. P. (2017). The structure of common emotion regulation strategies: A meta-analytic examination. Psychological Bulletin, 143(4), 384-427. https://doi.org/10.1037/bul0000093

Nelis, S., Luyckx, K., Feldman, G., Bastin, M., Raes, F., \& Bijttebier, P. (2016). Assessing response styles to positive affect: One or two dimensions of positive rumination in the Responses to Positive Affect questionnaire? Personality and Individual Differences, 89, 40-46. https://doi.org/10.1016/j.paid.2015.09.031

Nelis, S., Bastin, M., Raes, F., \& Bijttebier, P. (2018). When do good things lift you up? Dampening, enhancing, and uplifts in relation to depressive and anhedonic symptoms in early adolescence. Journal of Youth and Adolescence, 47(8), 1712-1730. doi:10.1007/s10964-018-0880-Z

Nezlek, J. B. (2017). A practical guide to understanding reliability in studies of within-person variability. Journal of Research in Personality, 69, 149-155. http://dx.doi.org/10.1016/j.jrp.2016.06.020

Nolen-Hoeksema, S. (1996). Chewing the Cud and Other Ruminations. In R. S. Wyer, Jr. (Ed.), Advances in Social Cognition, Vol. 9. Ruminative Thoughts (pp. 135-144). Lawrence Erlbaum Associates, Inc.

Nolen-Hoeksema, S., Stice, E., Wade, E., \& Bohon, C. (2007). Reciprocal relations between rumination and bulimic, substance abuse, and depressive symptoms in female adolescents. Journal of Abnormal Psychology, 116(1), 198207. https://doi.org/10.1037/0021-843X.116.1.198 
CAmerican Psychological Association, 2021. This paper is not the copy of record and may not exactly replicate the authoritative document published in the APA journal. Please do not copy or cite without author's permission.

Nook, E. C., Sasse, S. F., Lambert, H. K., McLaughlin, K. A., \& Somerville, L. H. (2017). Increasing verbal knowledge mediates development of multidimensional emotion representations. Nature Human Behaviour, 1(12), 881-889. https://doi.org/10.1038/s41562-017-0238-7

Nook, E. C., Sasse, S. F., Lambert, H. K., McLaughlin, K. A., \& Somerville, L. H. (2018). The nonlinear development of emotion differentiation: Granular emotional experience is low in adolescence. Psychological Science, 29(8), 1346-1357. DOI: $10.1177 / 0956797618773357$

Nook, E. C., Stavish, C. M., Sasse, S. F., Lambert, H. K., Mair, P., McLaughlin, K. A., \& Somerville, L. H. (2020). Charting the development of emotion comprehension and abstraction from childhood to adulthood using observer-rated and linguistic measures. Emotion, 20(5), 773-792. http://dx.doi.org/10.1037/emo0000609

Peters, J. R., Smart, L. M., \& Baer, R. A. (2015). Dysfunctional responses to emotion mediate the cross-sectional relationship between rejection sensitivity and borderline personality features. Journal of Personality Disorders, 29(2), 231240. https://doi.org/10.1521/pedi 201428151

Pfeifer, J. H., \& Berkman, E. T. (2018). The development of self and identity in adolescence: Neural evidence and implications for a value-based choice perspective on motivated behavior. Child Development Perspectives, 12(3), 158-164. https://doi.org/10.1111/cdep.12279

Pfeifer, J. H., Kahn, L. E., Merchant, J. S., Peake, S. J., Veroude, K., Masten, C. L., ... \& Dapretto, M. (2013). Longitudinal change in the neural bases of adolescent social self-evaluations: effects of age and pubertal development. Journal of 
CAmerican Psychological Association, 2021. This paper is not the copy of record and may not exactly replicate the authoritative document published in the APA journal. Please do not copy or cite without author's permission.

Neuroscience, 33(17), 7415-7419. https://doi.org/10.1523/JNEUROSCI.4074$\underline{12.2013}$

Quoidbach, J., Berry, E. V., Hansenne, M., \& Mikolajczak, M. (2010). Positive emotion regulation and well-being: Comparing the impact of eight savoring and dampening strategies. Personality and Individual Differences, 49(5), 368-

373. https://doi.org/10.1016/j.paid.2010.03.048

R Core Team. (2018). R: A language and environment for statistical computing. Vienna, Austria: R Foundation for Statistical Computing. Retrieved from www.R-project.org

Raes, F., Smets, J., Nelis, S., \& Schoofs, H. (2012). Dampening of positive affect prospectively predicts depressive symptoms in non-clinical samples. Cognition and Emotion, 26(1), 75-82. https://doi.org/10.1080/02699931.2011.555474

Rapee, R. M., Oar, E. L., Johnco, C. J., Forbes, M. K., Fardouly, J., Magson, N. R., \& Richardson, C. E. (2019). Adolescent development and risk for the onset of socialemotional disorders: A review and conceptual model. Behaviour Research and Therapy, 123, Article 103501. https://doi.org/10.1016/j.brat.2019.103501.

Rodman, A. M., Powers, K. E., \& Somerville, L. H. (2017). Development of self-protective biases in response to social evaluative feedback. Proceedings of the National Academy of Sciences, 114(50), 13158-13163. https://doi.org/10.1073/pnas.1712398114

Salk, R. H., Petersen, J. L., Abramson, L. Y., \& Hyde, J. S. (2016). The contemporary face of gender differences and similarities in depression throughout adolescence: Development and chronicity. Journal of Affective Disorders, 205, 28-35. http://dx.doi.org/10.1016/j.jad.2016.03.071 
CAmerican Psychological Association, 2021. This paper is not the copy of record and may not exactly replicate the authoritative document published in the APA journal.

Please do not copy or cite without author's permission.

Schäfer, J. Ö., Naumann, E., Holmes, E. A., Tuschen-Caffier, B., \& Samson, A. C. (2017). Emotion regulation strategies in depressive and anxiety symptoms in youth: A metaanalytic review. Journal of Youth and Adolescence, 46(2), 261-

276. https://doi.org/10.1007/s10964-016-0585-0

Shafir, R., Schwartz, N., Blechert, J., \& Sheppes, G. (2015). Emotional intensity influences pre-implementation and implementation of distraction and reappraisal. Social Cognitive and Affective Neuroscience, 10(10), 1329-

1337. https://doi.org/10.1093/scan/nsv022

Shahar, G., Rogers, M. L., Shalev, H., \& Joiner, T. E. (2020). Self-criticism, interpersonal conditions, and biosystemic inflammation in suicidal thoughts and behaviors within mood disorders: A bio-cognitive-interpersonal hypothesis. Journal of Personality, 88(1), 133-145. DOI: 10.1111/jopy.12446

Shapero, B. G., Stange, J. P., Goldstein, K. E., Black, C. L., Molz, A. R., Hamlat, E. J., Black, S. K., Boccia, A. S., Abramson, L. Y., \& Alloy, L. B. (2015). Cognitive styles in mood disorders: Discriminative ability of unipolar and bipolar cognitive profiles. International Journal of Cognitive Therapy, 8(1), 35-

60. https://doi.org/10.1521/ijct.2015.8.1.35

Sheppes, G. (2020). Transcending the "good \& bad" and "here \& now" in emotion regulation: Costs and benefits of strategies across regulatory stages. In Advances in Experimental Social Psychology (Vol. 61, pp. 185-236). Academic Press.

Sheppes, G., \& Meiran, N. (2007). Better late than never? On the dynamics of online regulation of sadness using distraction and cognitive reappraisal. Personality and Social Psychology Bulletin, 33(11), 1518-

1532. https://doi.org/10.1177/0146167207305537 
CAmerican Psychological Association, 2021. This paper is not the copy of record and may not exactly replicate the authoritative document published in the APA journal.

Please do not copy or cite without author's permission.

Sheppes, G., Brady, W. J., \& Samson, A. C. (2014). In (visual) search for a new distraction: The efficiency of a novel attentional deployment versus semantic meaning regulation strategies. Frontiers in Psychology, 5, Article

346. https://doi.org/10.3389/fpsyg.2014.00346

Sheppes, G., Suri, G., \& Gross, J. J. (2015). Emotion regulation and

psychopathology. Annual review of clinical psychology, 11, 379-405. doi:

10.1146/annurev-clinpsy-032814-112739

Shin, K. E., Newman, M. G., \& Jacobson, N. C. (2021). Emotion network density is a potential clinical marker for anxiety and depression: Comparison of ecological momentary assessment and daily diary. British Journal of Clinical Psychology. DOI:10.1111/bjc.12295

Siu, A. M. H., \& Shek, D. T. L. (2010). Social problem solving as a predictor of well-being in adolescents and young adults. Social Indicators Research, 95(3), 393406. https://doi.org/10.1007/s11205-009-9527-5

Svaldi, J., Griepenstroh, J., Tuschen-Caffier, B., \& Ehring, T. (2012). Emotion regulation deficits in eating disorders: A marker of eating pathology or general psychopathology? Psychiatry Research, 197(1-2), 103-

111. https://doi.org/10.1016/j.psychres.2011.11.009

te Brinke, L. W., Menting, A. T., Schuiringa, H. D., Zeman, J., \& Deković, M. (2020). The structure of emotion regulation strategies in adolescence: Differential links to internalizing and externalizing problems. Social Development. Advance Online Publication. https://doi.org/10.1111/sode.12496 
CAmerican Psychological Association, 2021. This paper is not the copy of record and may not exactly replicate the authoritative document published in the APA journal. Please do not copy or cite without author's permission.

Treynor, W., Gonzalez, R., \& Nolen-Hoeksema, S. (2003). Rumination reconsidered: A psychometric analysis. Cognitive Therapy and Research, 27(3), 247259. https://doi.org/10.1023/A:1023910315561

Trull, T. J., \& Ebner-Priemer, U. W. (2020). Ambulatory assessment in psychopathology research: A review of recommended reporting guidelines and current practices. Journal of Abnormal Psychology, 129(1), 56-63. https://doi.org/10.1037/abn0000473

van Buuren, S., \& Groothuis-Oudshoorn, K. (2011). mice: Multivariate imputation by chained equations in R. Journal of Statistical Software, 45, 1-67. DOI: 10.18637/jss.v045.i03

van den Heuvel, M., Stikkelbroek, Y., Bodden, D., \& Van Baar, A. (2020). Coping with stressful life events: Cognitive emotion regulation profiles and depressive symptoms in adolescents. Development and Psychopathology, 32(3), 985-995. doi:10.1017/S0954579419000920

Verstraeten, K., Vasey, M. W., Raes, F., \& Bijttebier, P. (2012). The mediational role of responses to positive affect in the association between temperament and (hypo) manic symptoms in children. Cognitive Therapy and Research, 36(6), 768-775. https://doi.org/10.1007/s10608-011-9402-y

Watkins, E. R., \& Roberts, H. (2020). Reflecting on rumination: Consequences, causes, mechanisms and treatment of rumination. Behaviour Research and Therapy, 127, 103573. https://doi.org/10.1016/j.brat.2020.103573

Webb, T. L., Miles, E., \& Sheeran, P. (2012). Dealing with feeling: A meta-analysis of the effectiveness of strategies derived from the process model of emotion 
CAmerican Psychological Association, 2021. This paper is not the copy of record and may not exactly replicate the authoritative document published in the APA journal. Please do not copy or cite without author's permission.

regulation. Psychological Bulletin, 138(4), 775-

808. https://doi.org/10.1037/a0027600

Wood, J. V., Heimpel, S. A., \& Michela, J. L. (2003). Savoring versus dampening: Selfesteem differences in regulating positive affect. Journal of Personality and Social Psychology, 85(3), 566-580. https://doi.org/10.1037/0022-3514.85.3.566

Zhang, J., Deng, X., Huang, L., Zeng, H., Wang, L., \& Wen, P. (2019). Profile of trait mindfulness and its association with emotional regulation for early adolescents. Personality and Individual Differences, 147, $12-$ 17. https://doi.org/10.1016/j.paid.2019.04.008

Zimmer-Gembeck, M. J., \& Skinner, E. A. (2011). Review: The development of coping across childhood and adolescence: An integrative review and critique of research. International Journal of Behavioral Development, 35(1), 117. https://doi.org/10.1177/0165025410384923 
CAmerican Psychological Association, 2021. This paper is not the copy of record and may not exactly replicate the authoritative document published in the APA journal. Please do not copy or cite without author's permission.

Table 1. Demographic characteristics by gender.

\begin{tabular}{llll}
\hline & Boys $(n=65)$ & Girls $(n=70)$ & \\
\hline Age & $11.54(S D=2.05$, & $12.14(S D=2.18$, range & $t(133)=1.66, n s$ \\
& range $=8-15)$ & $=8-15)$ & \\
Caucasian or white & $46(70.8 \%)$ & $48(68.6 \%)$ & $\chi^{2}(6)=3.13, n s$ \\
American Indian, Native & $0(0 \%)$ & $2(2.9 \%)$ & \\
American, or Alaska & & \\
native & & \\
Asian or Asian American & $6(9.2 \%)$ & $4(5.7 \%)$ \\
Black, African American, & $5(7.7 \%)$ & $5(7.1 \%)$ \\
or African & & \\
Latino or Hispanic & $4(6.2 \%)$ & $4(5.7 \%)$ \\
Middle Eastern or Arab & $2(3.1 \%)$ & $3(4.3 \%)$ \\
Mixed & $2(3.1 \%)$ & \\
\hline
\end{tabular}


CAmerican Psychological Association, 2021. This paper is not the copy of record and may not exactly replicate the authoritative document published in the APA journal.

Please do not copy or cite without author's permission.

Table 2. Means, standard deviations, and intraclass correlation coefficients.

\begin{tabular}{lcccccc}
\hline & $M_{\text {within }}$ & $S D_{\text {within }}$ & $S D_{\text {between }}$ & Range & Rithin & Range between $^{\text {ICC }}$ \\
\hline Self-criticism & 1.54 & 0.49 & 0.68 & $1.14-2.40$ & $1-5$ & .65 \\
Rumination & 0.79 & 0.66 & 0.52 & $0.21-2.02$ & $0-4$ & .39 \\
Distraction & 1.20 & 0.91 & 0.93 & $0.27-2.89$ & $0-4$ & .51 \\
Problem-solving & 0.94 & 0.81 & 0.83 & $0.19-2.38$ & $0-4$ & .52 \\
Dampening & 1.40 & 0.64 & 0.56 & $0.58-2.52$ & $0-4$ & .44 \\
EPR ${ }^{1}$ & 2.09 & 0.79 & 0.83 & $0.79-3.30$ & $0-4$ & .52 \\
SPR & 1.91 & 0.74 & 0.89 & $0.81-3.06$ & $0-4$ & .59 \\
Depressive symptoms & 2.70 & 1.82 & 3.00 & $0.99-6.14$ & $0-20$ & .73 \\
\hline
\end{tabular}

${ }^{1}$ EPR: Emotion-focused positive rumination; SPR: Self-focused positive rumination 
CAmerican Psychological Association, 2021. This paper is not the copy of record and may not exactly replicate the authoritative document published in the APA journal.

Please do not copy or cite without author's permission.

Estimated contemporaneous relationships

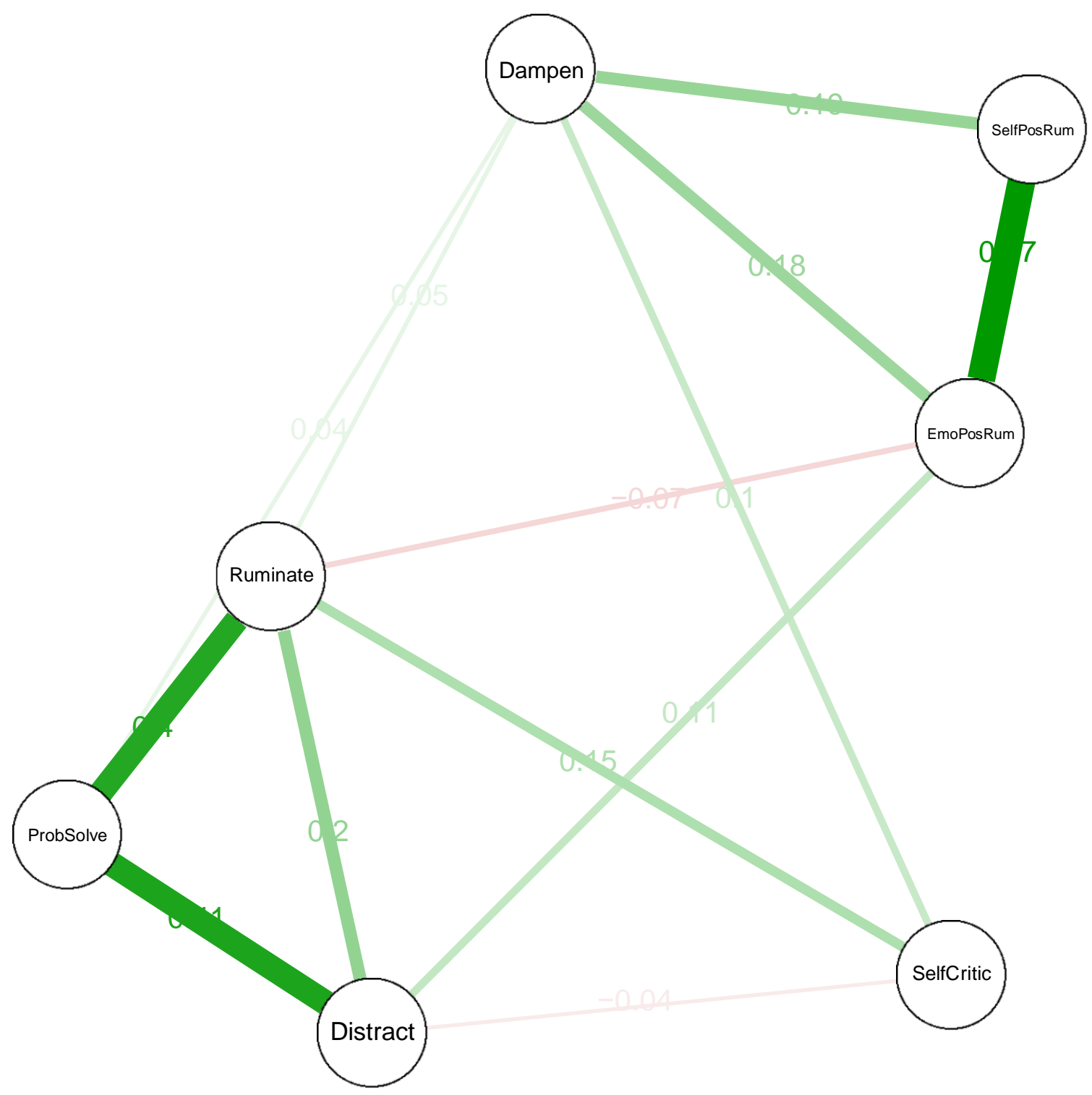


CAmerican Psychological Association, 2021. This paper is not the copy of record and may not exactly replicate the authoritative document published in the APA journal.

Please do not copy or cite without author's permission.

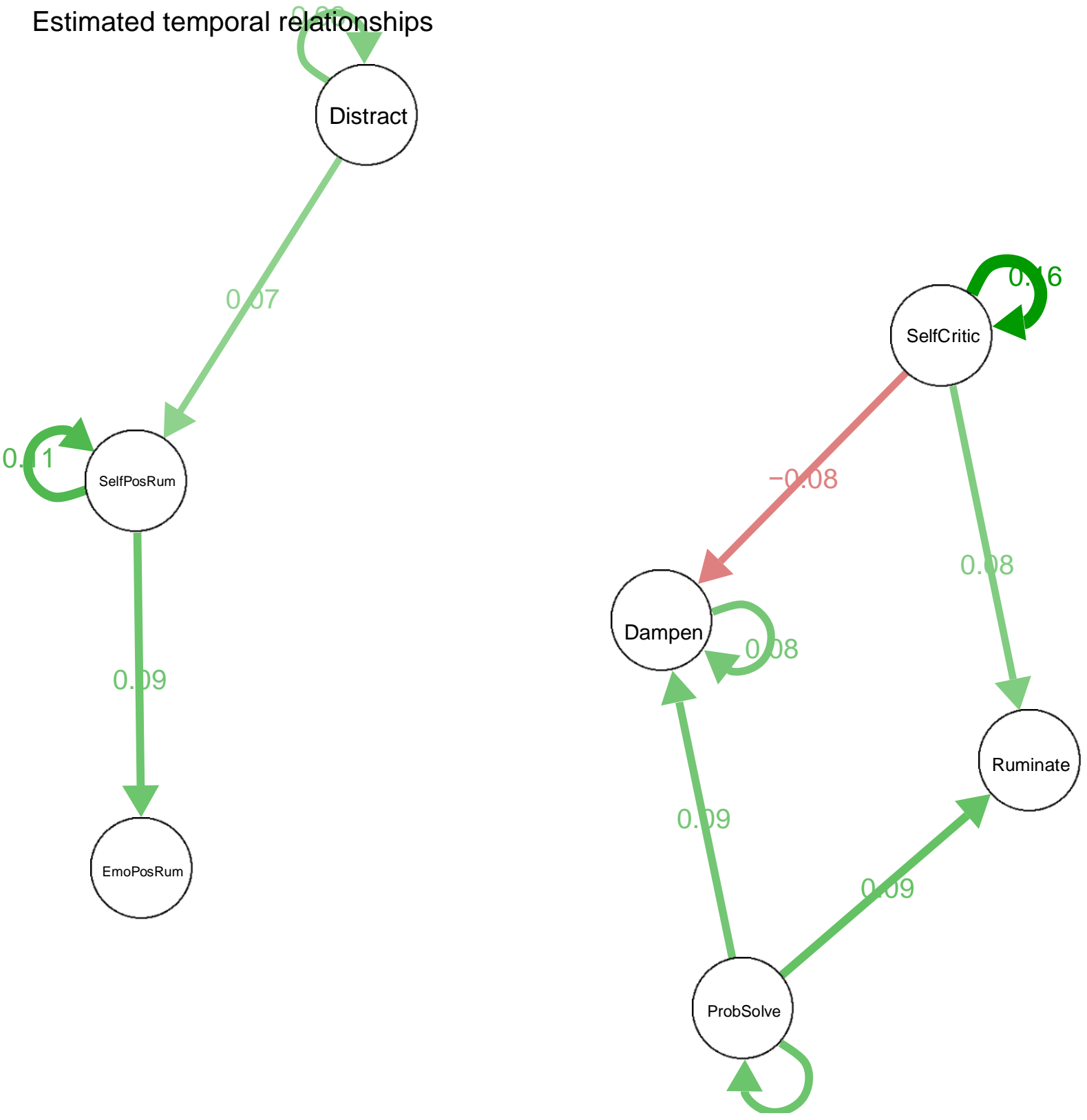


CAmerican Psychological Association, 2021. This paper is not the copy of record and may not exactly replicate the authoritative document published in the APA journal.

Please do not copy or cite without author's permission.

Estimated between-subjects relationships

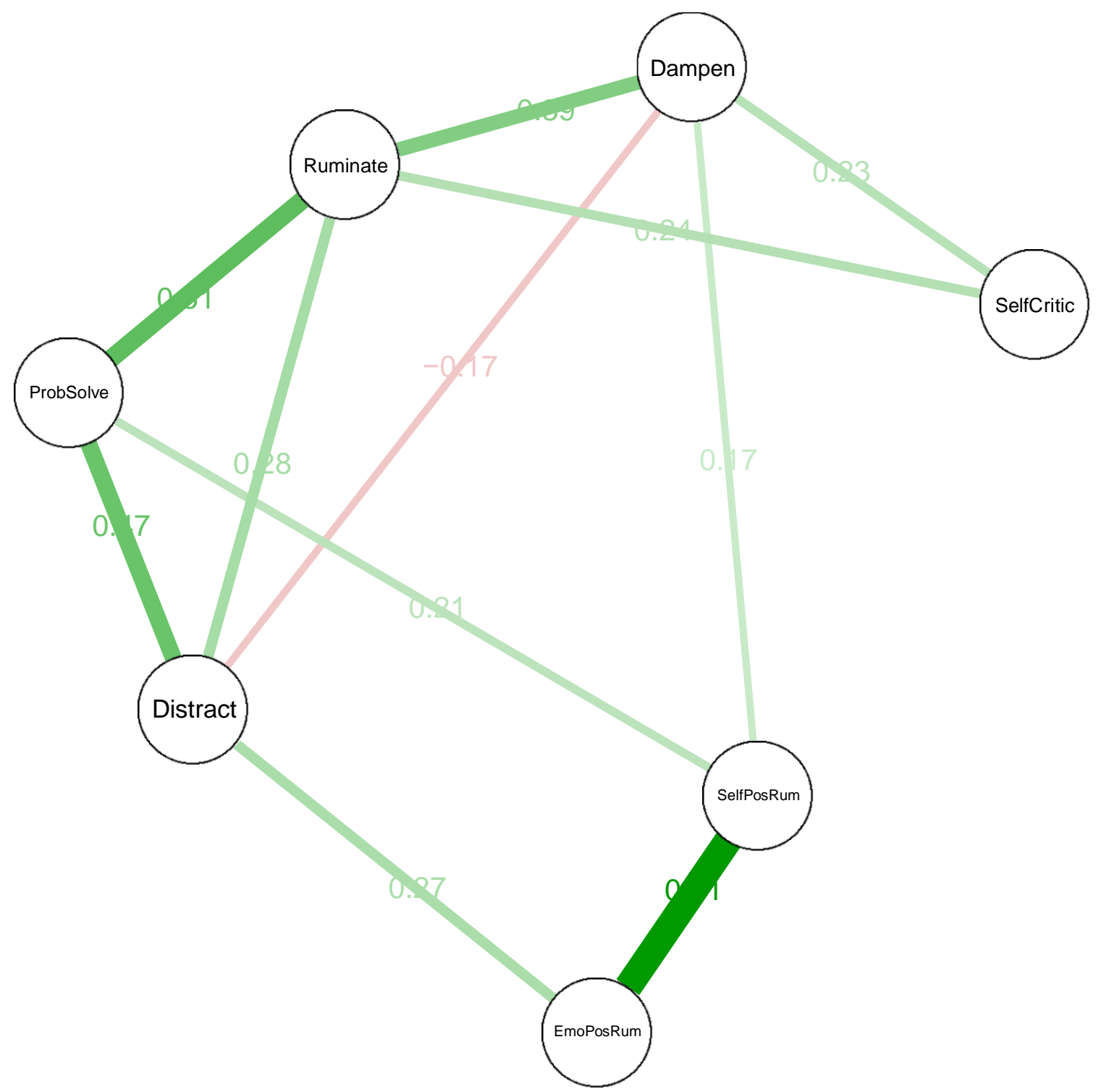

